\title{
O trabalhador no centro de propostas de pesquisa- formação para o trabalho associado
}

Maria Clara Bueno Fischer*

\section{Resumo:}

As reflexôes apresentadas neste artigo têm como objetivo contribuir com a análise e a elaboração de pressupostos teórico-metodológicos de projetos de formação direcionados à afirmação e autonomia de sujeitos envolvidos em experiências de trabalho associado, tendo como horizonte político a luta por um trabalho e uma sociedade em que seja afirmado o princípio da autogestão como um de seus pilares fundamentais. Para tal, a autora analisa o potencial da abordagem ergológica do trabalho e da perspectiva teórica conhecida como abordagem biográfica temática ("histórias de vida" a serviço do desenvolvimento de projetos).

Palavras-chave: Trabalho. Trabalhadores-Formação. Trabalhadores-Experiências.

\footnotetext{
* Professora da Universidade do Vale do Rio dos Sinos - UNISINOS. Atua no curso de Pedagogia e no Programa de Pós-Graduação em Educação, Linha de Pesquisa: Educação e Processos de Exclusão Social. Doutora em Educação pela Universidade de Nottingham, Reino Unido.
} 


\section{Introdução}

Nas últimas décadas, têm se observado indícios internacionais significativos de retomada da luta coletiva, com destaque para o caso brasileiro, no sentido de realização de experiências de trabalho com base nos princípios da autogestão e da solidariedade. Referimo-nos ao que tem se chamado de economia solidária, economia popular e solidária, socioeconomia solidária, empresas autogestionárias, entre tantas outras denominações. Singer (2003, p. 116) afirma que

[...] o conceito se refere a organizações de produtores, consumidores, poupadores, etc., que se distinguem por duas especificidades: (a) estimulam a solidariedade entre os membros mediante a prática da autogestão e (b) praticam a solidariedade para com a população trabalhadora em geral, com ênfase na ajuda aos desfavorecidos.

A formação para os trabalhadores envolvidos em experiências de trabalho associado tem se tornado uma variável-chave para que elas se solidifiquem efetivamente na perspectiva da autogestão. Este artigo busca contribuir para o enfrentamento deste desafio. Nesse sentido, um dos argumentos que permeia a reflexão é a defesa da importância de o sujeito trabalhador apropriar-se, de forma crítica, individual e coletivamente, do conteúdo e do processo de sua formação ao longo da vida, mais particularmente daquela ocorrida em experiências de trabalho pregressas para ser cotejada com a formação que está acontecendo em situações de trabalho atuais. A hipótese é que tal apropriação contribui com a realização da condição ontológica do trabalhador como ser humano. Ser de práxis que faz história porque transforma o mundo natural e cultural em que está inserido.

Sistematizar e analisar a formação que ocorre consigo e com seus pares no trabalho é especialmente relevante para os envolvidos em formas de trabalho associado e sociedades inspiradas na autogestão, porque permitem que realizem a articulação consciente e crítica entre o seu patrimônio - de práticas e de conhecimentos - como indivíduo, grupo e classe. Intrinsecamente relacionada à tomada de consciência da sua condição histórica, está a atitude do sujeito de conceber-se como um ser que faz escolhas em micro e macrossituações. Isto é, reconhecer sua autonomia, 
mesmo que relativa, na condução de micro e macrossituações de trabalho e sociais. Referimo-nos, aqui, às dimensões éticas e políticas, próprias dos seres humanos, que são centrais na condução da vida individual e coletiva. Na condição de criadores do "novo" no contexto do "velho", os trabalhadores associados necessitam retomar, conscientemente, elementos fundamentais de constituição ontológica do ser humano, expressas nas suas experiências.

Esse horizonte político e filosófico tem nos orientado no que diz respeito ao estudo de "modos de produção e legitimação de saberes" de trabalhadores. Neste sentido, temos analisado o potencial de dois referenciais teórico-metodológicos: abordagens biográficas temáticas; isto é, o trabalho com histórias de vida a serviço de projetos, e, também, a Ergologia. Argumentamos que estes podem ter um lugar central para a elaboração de projetos de pesquisa-formação para o trabalho associado. Estes referenciais se complementam porque contribuem para o conhecimento e análise das marcas formadoras das biografias dos indivíduos; da sua cultura de classe; do patrimônio desenvolvido pelo sujeito na atividade (viva) de trabalho e, ainda, para a apropriação individual e coletiva da experiência. Estes são elementos fundamentais para o desenvolvimento do protagonismo - individual e coletivo - dos trabalhadores na implementação e consolidação de experiências de trabalho associado. Entendemos, então, que tais perspectivas teóricas são relevantes para fundamentar programas de pesquisa-formação de trabalhadores porque contribuem com o conhecimento de "modos de produção e legitimação de saberes" dos trabalhadores.

\section{Produção e legitimação de saberes para e no trabalho}

Podemos considerar, grosso modo, como legitimação de saberes os atos (e os efeitos deles derivados) de reconhecer e dar validade individual, coletiva e social aos saberes e às experiências que alguém possui, conferindoThe legitimidade. Tais procedimentos têm caráter histórico e envolvem conflitos que, por sua vez, demandam de cada sociedade a criação de rituais e modos singulares para operar a validação e legitimação dos saberes e experiências produzidos pelos seus membros.

Nas sociedades capitalistas modernas, no topo da hierarquia dos saberes que são socialmente valorizados, encontram-se aqueles incorporados 
na tecnologia e no conhecimento científico legitimados, reconhecidos e validados socialmente por possuírem valor de uso, simbólico e de troca. É no trabalho vivo, na atividade real do trabalhador, que os saberes da experiência individual e coletiva, muitas vezes denominados de saberes tácitos, são articulados com os saberes científicos.

Em iniciativas de trabalho associado, a questão dos saberes torna-se complexa, pois se trata de identificar, reconhecer e analisar criticamente saberes produzidos em atividades pregressas de trabalho assalariado, ou mesmo informal, numa perspectiva de continuidade e, ao mesmo tempo, de ruptura com a experiência e os saberes necessários e produzidos no próprio trabalho associado. Este, muitas vezes, se institui em condições materiais precárias. A realização de experiências de trabalho associado está, assim, numa relação dialética de afirmação e de superação da história e da cultura da própria classe trabalhadora.

Investigar o cotidiano da atividade de trabalho associado parecenos um caminho fértil para conhecer com os trabalhadores aspectos fundamentais das situações-limite que se impõem e se criam no cotidiano e, por outro lado, as possibilidades para realizarem o "inédito viável" a que se propõem. A abordagem biográfica temática e a Ergologia se situam como perspectivas promissoras de investigação-formação da atividade de trabalho e dos modos de produção de saberes e, é claro, dos próprios saberes, dos trabalhadores.

\section{A contribuição da Ergologia para compreender a dimensão subjetiva nos modos de produção e legitimação de saberes para e no trabalho associado}

A Ergologia tem se preocupado especialmente com a atividade humana do trabalho, considerada como atividade industriosa. ${ }^{2}$ Nesta perspectiva teórica, a acuidade do olhar para conhecer o trabalho está dirigida para a atividade de trabalho, no seu processo real. Assume-se que no trabalho real ${ }^{3}$ são produzidos valores e saberes não perceptiveis imediatamente. "Ergologia é a aprendizagem permanente dos debates de normas e de valores que renovam indefinidamente a atividade: é o desconforto intelectual" (SCHWARTZ; DURRIVE, 2007, p. 30). A atividade é constituída de três características: 
a - transgressão: expressa as tensões entre o que é formalizado pelas normas e conceitos e o informal, o que não é bem codificado ao nível $\mathrm{da}$ linguagem; b - mediaf̧ão: aspecto dinâmico dessa transgressão que, nas atividades de trabalho, se apresenta como algo obscuro porque se encontra incorporado nos corpos dos sujeitos; c-contradif̧ão: instaura um debate de normas em que cada sujeito é convocado a getir quotidianamente suas ações. (BRITO, 2006, p. 3-4).

Esta abordagem desafia os interessados ao exercício da investigação transdisciplinar e de mútua confrontação e interlocução entre saberes investidos da experiência de trabalho e saberes acadêmicos. $\mathrm{A}$ abordagem ergológica e a Análise Pluridisciplinar de Situações de Trabalho (APST) vêm sendo desenvolvidas pelo Departamento de Ergologia da Universidade de Provence - França, criado em 1997. ${ }^{4}$ Estudos sobre atividades de trabalho - em geral, heterogeridas - em diferentes setores da economia têm, crescentemente, se utilizado desta abordagem para melhor apreender a complexidade das novas configurações do trabalho, incluindo, entre outros aspectos, as mudanças estruturais e o lugar da subjetividade do trabalhador nelas.

Com menos freqüência, são encontrados estudos, com base na Ergologia, para entender as especificidades do trabalho associado. Nossa tentativa é elaborar e desenvolver hipóteses sobre o valor desta abordagem para conhecer mais profundamente a atividade de trabalho e os modos possivieis de sua apropriação pelos próprios trabalhadores, qualificando a realização de pesquisa-formação com trabalhadores. A experiência de formação/investigação que vem sendo desenvolvida pelo Departamento de Ergologia francês e o trabalho de investigação-formação que vem sendo realizado por pesquisadores em Educação no Brasil nos estimulam a estudar o potencial da Ergologia para estudos voltados para a formação de trabalhadores. ${ }^{5}$

Tomemos uma observação de Schwartz (2007, p. 37), ao ser perguntado sobre as possibilidades da Ergologia em termos de o sujeito transformar a atividade de trabalho; ou seja, o quanto a perspectiva 
ergológica incorpora ou potencializa uma intencionalidade transformadora do trabalho. $\mathrm{O}$ autor afirma que a "....] ergologia constitui-se em um projeto de melhor conhecer e, sobretudo, de melhor intervir sobre as situações de trabalho para transformá-las".

Penso que levar a sério a noção de atividade é justamente o reconhecimento de que não há situação de trabalho que já não seja, mais ou menos, transformadora ou tentativa de transformação. Existem, na própria atividade, reservas de alternativas permanentes que são mais ou menos contrariadas, mais ou menos desenvolvidas - eu diria de relevâncias e influências muito variáveis.

Mas a idéia de atividade é sempre um "fazer de outra forma", um "trabalhar de outra forma". Não é uma palavra de ordem projetada no futuro: está dentro da realidade, é uma espécie de obrigação mesma de qualquer situação de atividade de trabalho humano já incluir a transformação. (SCHWARTZ, 2007, p. 34-35).

Quando nos referimos às experiências do trabalho associado, inseridas no contexto da formação social capitalista, temos como pressuposto a transformação do trabalho heterogerido em trabalho autogerido, cujos meios de produção são propriedade dos trabalhadores. Estamos nos referindo ao tensionado embate entre uma forma de atividade de trabalho marcada pela prescrição e usurpação da autonomia do sujeito (na qual reinam a modelagem do sujeito e sua adaptação) e outra orientada pelo seu oposto (o sujeito que modela e intervém, cria e projeta). Segundo a abordagem ergológica, nem a forma mais dura de aplicação do manual taylorista de organização do trabalho consegue impedir algum nível, mesmo que mínimo, de renormatização da atividade de trabalho através do uso que o trabalhador faz de si.

Schwartz (2007) afirma que, em qualquer atividade de trabalho, temos:

- a existência de uma distância entre o trabalho prescrito e o trabalho real';

- que tal distância é sempre ressingularizada; 
- o "corpo-si" é o ente que conduz e arbitta esta distância; e, ainda,

- que o ato de arbitrar supõe escolhas que mobilizam um complexo de valores; refere-se, neste caso, às “dramáticas do uso de si”" (referese ao uso de si por si mesmo e do uso de si pelos outros).

$A$ atividade de trabalho media a relação do sujeito com o meio, expressa contradições e transgressões.

Um aspecto importante deste referencial, que se faz necessário pontuar, mesmo que de forma breve, é como ele discute as dimensões micro e macro (sociais, históricas, etc.) presentes na realização da atividade de qualquer trabalho. Sem esta clareza, poderíamos estar nos inclinando a sobrevalorizar a singularidade do trabalho real (e, portanto, do trabalho concreto) e as possibilidades de uso de si do trabalhador, perdendo, conseqüentemente, a dimensão das relações que existem entre parte e totalidade. $O$ posicionamento adotado por aqueles que vêm desenvolvendo a abordagem ergológica, que nos parece esclarecedor, é de que as questões mais amplas podem ser lidas na atividade singular de trabalho - há uma relação entre esta singularidade e a totalidade histórica e social - e, ainda, que há uma relação de mútua determinação entre o contexto e a vida das pessoas fora do trabalho com o que acontece no trabalho. Todavia, tal relação não deve ser estabelecida numa lógica descendente, e sim numa perspectiva dinâmica e dialética. Este posicionamento afirma a dimensão de mediação que é materializada na atividade de trabalho. Nossa interpretação é que a Ergologia permite aprofundar a relação entre totalidade, parte e singularidade, a partir desta. Isto é, esta abordagem possui uma riqueza conceitual que contribui para pensar como o trabalho abstrato e o concreto se produzem através da atividade singular de trabalho. Parece-nos que nos auxilia a fazer uma leitura do lugar do sujeito individual e do sujeito coletivo no trabalho como acontece hoje e na sua prospecção.

No caso das experiências de trabalho associado, nossa compreensão é que a análise da atividade de trabalho, na perspectiva ergológica, colabora significativamente para estudar, por exemplo, sobre as possíveis explicações para as relações de não-linearidade entre o proposto e o realizado no campo da economia solidária. As diferenças, por exemplo, entre as normatizações oriundas dos conhecimentos propostos como um "dever ser" (as normas 
do campo da economia popular e solidária, as expressas nos estatutos dos empreendimentos, nos seus regimentos internos, nas suas definições coletivas, entre outras formas de prescrição) e as renormatizações ocorridas no cotidiano da atividade de trabalho associado. A microgestão do trabalho é algo constitutivo de qualquer forma de trabalho. Afirmar tal questão é se contrapor à idéia mais ou menos comum de que somente os "gestores" realizam gestão sobre a atividade de trabalho. Assim, não é a instauração de uma proposta de trabalho associado e autogestionário que inaugura a idéia e a prática de gestão do trabalhador de seu trabalho. É claro que, neste caso, ela se potencializa e vira autogestão efetiva do trabalho como um todo. Isto significa pensar que há elos de continuidade e descontinuidade entre uma e outra forma de trabalho.

O uso de si por si mesmo, na microgestão do trabalho, remete à reflexão sobre a produção de saberes em situação de trabalho. De acordo com Schwartz (2003, p. 23):

[...] toda a atividade de trabalho encontra saberes acumulados nos instrumentos, nas técnicas, nos dispositivos coletivos; toda a situação de trabalho está saturada de normas de vida, de formas de exploração da natureza e dos homens uns pelos outros.

Isso produz aprendizagens e imprendizagens.

São saberes de um corpo-si, construídas na história singular (ao longo da trajetória de vida), no seio das experiências vividas anteriormente, mas que interagem com as situações vividas no momento presente podendo ser reforçado, re-processado, re-trabalhado. É este patrimônio pessoal que se coloca em marcha nas atividades desenvolvidas pelo corpo-si que podem me fornecer os raios de ação dentro da situação, explorando, por exemplo, "reservas de alternativas". (CUNHA, 2007a, p. 6).

Por fim, faz-se necessário trazer aqui o tema do Dispositivo Dinâmico a Três Pólos. Esta proposição ergológica tem uma contribuição específica e singular para o debate sobre a produção de conhecimento sobre o trabalho, especialmente sobre os lugares e as relações entre a 
dimensão conceitual e a experiencial do conhecimento. É um "dispositivo" em que o primeiro pólo é aquele dos conceitos e dos saberes constituídos. Os sujeitos deste pólo são aqueles dedicados à produção dos saberes acadêmicos. No segundo pólo, estão os sujeitos da atividade. É o lugar dos saberes investidos na atividade de trabalho, que são dificeis de serem formulados em seqüências lineares e desafiam os saberes acadêmicocientíficos, que tendem à generalização. São produzidos na atividade singular e expressam a história viva do trabalho, no seu acontecer, em que o patrimônio de saberes existentes é convocado e, ao mesmo tempo, outros se produzem. É o tempo do kairós. E o terceiro pólo é o das exigências éticas e epistemológicas de confrontação e mútua aprendizagem entre os sujeitos dos dois primeiros pólos. Este dispositivo foi criado pelo Departamento de Ergologia da Universidade de Provence para criar condições de co-produção dos objetivos, problemáticas e resultados das intervenções dos trabalhadores em situação de trabalho. A idéia do desconforto intelectual permanente, no que diz respeito ao conhecer a atividade de trabalho, provoca a assunção da necessidade ética, política e epistemológica de os sujeitos dos dois pólos se aproximarem e criarem o terceiro pólo. Este dispositivo implica abertura desses sujeitos para realizarem problematização e aprendizagem mútua. Tal abertura não significa uma perspectiva de relativismo epistemológico; significa, sim, um exercício de estranhamento mútuo, de consideração de que há uma vivência à espera de conceituação produzida na atividade de trabalho que, por natureza, é movimento e reinvenção.

Parece-nos que este Dispositivo provoca o avanço de nossas reflexões sobre o papel de mediação da pesquisa-formação no sentido de articular teoria e prática, especialmente no que diz respeito ao lugar dos saberes oriundos da experiência e dos saberes científicos. Provoca-nos a continuar as tentativas de romper com visões de linearidade e de ascendência ou descendência entre conhecimentos teóricos e empíricos, mas de uma relação dialética entre a experiência e conceito. Tal dispositivo contribui para nos pensarmos como sujeitos de práxis incompletas e mutuamente dependentes. Desafia-nos a enfrentar as contradições que experimentamos diariamente para produzir conhecimento numa sociedade de classes que cindiu e fragmentou o conhecimento. 


\section{Transformar "vivências" individuais e coletivas em "experiências formadoras"}

A experiência é uma palavra oriunda do latim experientia, do verbo experiri, que significa "experimentar". "Experiência" pode ser entendida como o fato de experimentar alguma coisa que amplia as possibilidades e enriquece o ser humano, individual e coletivamente, nas diversas dimensões que o compõem. Pode ser distinguida de uma vivência qualquer pela implicação e tomada de consciencia do sujeito daquilo que the acontece, tornando, então, a vivência uma experiência propriamente dita. É certo que, ao realizar algo, no próprio processo de fazê-lo, o sujeito atribui sentidos ao vivido produzindo para si marcas éticas, políticas, culturais e existenciais. Uma experiência coletiva cria modos de ser, de produção e de reprodução material, social e cultural de uma coletividade. Cria saberes e tradições num grupo social, numa instituição, num povo ou numa classe social. $O$ pensamento de E. P. Thompson sobre a categoria experiência é relevante para pensar a articulação entre saberes produzidos em situação de trabalho e a experiência de classe (VENDRAMINI, 2006).

A vida ensina, aprende-se com as próprias vivências. O processo e a manifestação de que se aprende ou não com elas pode se dar de diferentes formas. Pode-se, em função de uma aprendizagem, alterar a ação e atitude de forma direta, na própria prática. Isso não implica, no entanto, que o pensamento não esteja presente na ação. Ação já é pensamento em ato. Em determinados casos, o sujeito pode dar-se conta no próprio fazer que está aprendendo e mudando seu modo de ser e agir. Evidentemente, isso é um indicador de que algo se passou e que algo se aprendeu com o vivido. No entanto, além de mudar, na prática, pode-se compreender melhor como e por que passamos a fazer, pensar ou sentir de outro jeito. Neste caso, se está realizando um aprendizado mais consciente, tornando a vivência uma experiência propriamente dita e, mais ainda, uma experiência formadora. Formadora porque compreendida, apropriada pelo sujeito, podendo auxiliálo a construir ou modificar seus projetos de vida ou de formação.

A abordagem ergológica nos indica que, nas situações singulares da atividade de trabalho, os indivíduos se relacionam com ela a partir de "[...] suas histórias, seus itinerátios, sua vida pessoal em toda a sua complexidade" (SCHWARTZ, 2007, p. 49). Suas escolhas acontecem numa 
relação de tensão com as normas prescritas. Ao fazê-las, utilizam os saberes oriundos das suas histórias de vida, incluindo as vivências de trabalho pregressas. É por isso que identificamos, em articulação com a Ergologia, outra abordagem potencialmente rica para estudar iniciativas de trabalho associado e para fundamentar projetos de formação de trabalhadores; a pesquisa-formação.

Há muitos estudos no campo da pesquisa-formação que têm grande legitimidade, como possibilidade de produção de conhecimento, na área da Educação. Entre eles, está o desenvolvido por Josso (2004), que tem chamado a nossa atenção pela sua possível adaptação e reinvenção para pesquisa e formação com trabalhadores. Trata-se da sua reflexão a respeito da transformação das vivências de um sujeito em experiências formadoras. A autora trabalha com três modalidades de elaboração para compreender a experiência: "ter experiência, fazer experiência e pensar a experiência" (JOSSO, 2004, p. 51). “Ter experiências" está associado às situações em que se aprende, mas que não foram provocadas pelo sujeito; "fazer experiências" diz respeito às intencionalmente criadas; e a terceira modalidade, "pensar sobre as experiências", refere-se a criar situações para apropriar-se tanto das vivências não provocadas como aquelas provocadas. A autora discute sobre a combinação necessária entre momentos individuais e os coletivos para pensar sobre o vivido que nos forma e nos transforma: "caminhar para si" e "caminhar com". Momentos associados às dimensões subjetivas e intersubjetivas que são necessárias para a apropriação das vivências.

\section{Cotejando a teoria com a prática}

As reflexões teóricas acima apresentadas podem revestir-se de mais sentido se forem cotejadas com desafios colocados pela realidade. Em vista disso, apresentamos a seguir uma análise resultante de uma pesquisa feita com trabalhadores de uma cooperativa de calçados em que idéiaschave sobre pesquisa-formação e abordagem biográfica temática de Josso $(1999,2004)$ foram utilizadas. As discussões oriundas da Ergologia ainda não nos eram familiares, quando fizemos esta pesquisa. Foram indicadores empíricos e, obviamente, o acesso que tivemos a este referencial que nos levaram a identificar o seu potencial para outros estudos sobre formação e trabalho associado. 
Os objetivos principais da pesquisa a que estamos fazendo referência eram:

- identificar, sistematizar e analisar saberes produzidos pelos trabalhadores nos desafios cotidianos enfrentados em situação de trabalho na cooperativa em questão (considerada como uma experiência de trabalho associado);

- identificar, sistematizar e analisar saberes produzidos em situações pregressas de trabalho que os sujeitos associavam aos desafios atuais enfrentados na cooperativa;

- contribuir para qualificar propostas de formação para trabalhadores envolvidos em experiências de trabalho associado.

Cinco homens e cinco mulheres de uma cooperativa de calçados da região do Vale do Rio dos Sinos, próxima de Porto Alegre, foram entrevistados. Setenta trabalhadores eram associados da cooperativa; tinham entre trinta e sessenta anos, e sua escolaridade variava entre a $3^{2}$ série do Ensino Fundamental e o $1^{2}$ ano do Ensino Médio. Todos vieram da zona rural dos Estados de Santa Catarina e do norte do Rio Grande do Sul. Já tinham trabalhado, anteriormente, em indústrias de calçado da região do Vale dos Sinos. Desempregados, estabeleceram a cooperativa nos inícios dos anos 1990 com o apoio do sindicato local de trabalhadores do setor coureiro-calçadista. A cooperativa possuía sede e maquinário próprios, tendo sua produção definida, no entanto, pela dinâmica e demanda da indústria coureiro-calçadista da região. Até os inícios dos anos 2000, produziam calçados para uma grande empresa do setor que terceirizava parte de sua produção para a cooperativa. Houve um momento, no entanto, em que os pedidos diminuíram em função do rompimento do contrato com esta empresa. No período de realização da pesquisa, em 2005, os associados tentavam produzir um modelo de calçado próprio, além de aceitar outros pedidos esporádicos. A viabilização estava difícil em função dos altos custos envolvidos. Hoje, por falta de condições de sustentação econômica, a cooperativa está desativada. ${ }^{8}$

Elementos contraditórios importantes estavam presentes na constituição e no funcionamento da cooperativa. Como parte da cadeia produtiva de calçados e dependente de uma grande indústria, realizando de forma terceirizada parte de sua produção, a cooperativa contribuía para 
a realização dos fins definidos pela empresa contratante: o lucro. Como empreendimento econômico solidário, funcionava internamente com base em princípios solidários e democráticos (propriedade coletiva dos meios de produção; distribuição igualitária dos ganhos da produção, expressos no salário igual para todos; gestão democrática e ações de ajuda mútua). A relação de dependência com a grande indústria permitia produção constante e aperfeiçoamento técnico na produção do calçado. $O$ acompanhamento direto da empresa, treinando os trabalhadores e supervisionando a produção do calçado, promovia uma continuidade na qualificação dos trabalhadores. Esta, no entanto, estava diretamente associada a um padrão de produção e de venda de produtos determinado pelos valores de troca, próprios do mercado capitalista. Neste sentido, contrário aos horizontes político-econômicoideológicos do movimento pela autogestão no trabalho e na sociedade.

Essa relação de subordinação determinava, então, o titmo de produção. Os limites de horas de trabalho se esgarçavam para atingir o máximo de produção, garantindo maior renda. As desconfianças dos compradores dos serviços da cooperativa, pelo fato de que na cooperativa não havia a responsabilização individual (de um chefe e de um dono) pelos resultados da produção, provocavam questionamentos no grupo. Perguntavam-se, por exemplo, sobre se deveriam ou não se manter, oficial e publicamente, como cooperativa ou se deveriam tornar-se uma microempresa. Afinal, necessitavam que alguém comprasse os seus serviços. Aqui, além dos aspectos econômicos, outras questões estavam em jogo, como o próprio etos da cooperativa.

A luta por ter um "produto próprio" era considerada algo fundamental para que viessem a ter mais autonomia, pois seria uma alternativa de sustentação do empreendimento. Estavam cientes do risco que sofriam por serem dependentes de uma indústria em especial. Mesmo quando tinham seus serviços contratados de forma regular, havia momentos em que ficavam sem serviço. Nestes períodos, uma parcela pequena dos trabalhadores associados ficava no empreendimento, e a ampla maioria ia buscar serviço alhures. Muitos voltavam quando os seus serviços se tornavam necessátios novamente. Tal situação colocava, especialmente, para as lideranças, o desejo de produzir, efetivamente, um produto próprio, sem depender de outros. Estes indicadores relativos à dinâmica contraditória vivida retratam, mesmo que de forma breve, as contradições vividas por aqueles que tentam realizar a autogestão no trabalho no capitalismo. 
Essas breves informações a respeito da cooperativa servem como pano de fundo para perceber as dificuldades vividas pelos trabalhadores diretamente responsáveis pelo seu sucesso. Investigar formas de contribuir com a formação desses trabalhadores nos parece uma questão central. Obviamente, a formação é uma entre tantas outras variáveis para a consolidação dessas iniciativas de trabalho.

Um dos elementos-chave da teorização de Josso (2004) sobre pesquisa-formação foi utilizado por nós: o fato de ela servir para que os sujeitos transformassem suas "vivências" significativas em "experiências" formadoras. Processo que é desenvolvido numa combinação intencional de construções subjetivas e intersubjetivas; de escuta de si e do outro. Responde às perguntas: o que é a minha formação? Como me formei? $O$ que foi formador na minha trajetória? O que aconteceu para que eu desenvolvesse as idéias que eu tenho? Como as experiências da minha vida profissional contribuem para o sentido que dou àquilo que vivo hoje? $\mathrm{Na}$ pesquisa, priorizamos o foco da formação para o trabalho e, de forma mais especifica, para o trabalho cooperativo.

Nesta investigação, todos os entrevistados leram, na íntegra, a transcrição de suas narrativas, coletadas através de entrevistas individuais. A leitura ocorreu em seus lares e, do ponto de vista metodológico, significou um segundo momento de reflexão individual sobre suas vivências, tendo o primeiro ocorrido no próprio momento da entrevista. Esses dois momentos estão associados ao procedimento metodológico de "caminhar para si" indicado por Josso (2004). Posteriormente, foi realizado um encontro coletivo com as mulheres entrevistadas ${ }^{9}$ para a realização do momento do "caminhar com". Neste, aconteceram trocas intersubjetivas, através da retomada coletiva das narrativas de cada uma e da realização de diálogos reflexivos a respeito delas, sob a coordenação da pesquisadora. Este encontro foi cuidadosamente preparado também pelas próprias mulheres. Realizado no próprio local de trabalho, com comes e bebes trazidos pelas mulheres, constituiu-se num momento ímpar para elas e para nós. Relacionaram suas vivências significativas, individuais e, muitas vezes, semelhantes entre si, de produção de saberes em situações de trabalho, com especial destaque ao que diz respeito à cooperação.

Os trabalhadores e as trabalhadoras desta cooperativa de calçados tinham experiências de trabalho anteriores: trabalho doméstico, em empresas 
(da indústria calçadista), em ateliers de calçados, na comunidade (igreja e outras instituições) e, hoje, na cooperativa. Em cada um desses locus, saberes dos mais diversos foram produzidos $\mathrm{e} / \mathrm{ou}$ incorporados pelos sujeitos.

As mulheres aprenderam um conjunto de saberes relacionados às dimensões de fazer, ser e conviver no cuidado da casa e da familia. Saberes que vão sendo incorporados desde os primeiros anos de vida. A pedagogia que perpassou o aprender e o ensinar tais saberes foi a do exemplo, de ensaio-e-erro e da transmissão dos adultos para as crianças. A cooperação, como prática e como valor, foi sendo aprendida nas diferentes situações de ajuda e na divisão das tarefas domésticas e de trabalho na agricultura. As mulheres referiam-se à tradição quando tentavam explicar por que tal perspectiva de ser, estar e saber era ensinada.

O trabalho no campo, no caso das mulheres entrevistadas, era assumido por todos os membros da família. Para as mulheres, a familia e o trabalho formavam uma unidade indissociável. Todavia, embora todos trabalhassem, a divisão de tarefas na roça era determinada pelo pai. A socialização das crianças no espaço e no tempo do trabalho na agricultura, que se dava attavés do exemplo e da experiência direta, apareceu como a forma de educação (informal) mais significativa. Segundo as mulheres, os mais velhos respeitavam as possibilidades e o ritmo das crianças na realização das tarefas, e, além disso, todo o processo se revestia de uma importante dimensão lúdica. Assim, pode-se perceber que o trabalho na roça foi narrado pelas mulheres de forma positiva e identificado como uma experiência de união, de entre -ajuda. As marcas da dificuldade da vida no meio rural, que as trouxe para a cidade, ficaram subsumidas. $O$ que, por que e como se realizava o trabalho foi explicado como tespeito à tradição: Era assim que devia ser; sempre foi assim.

No periodo de sua vinda para a região industrial do Vale dos Sinos, no Rio Grande do Sul, o trabalho assalatiado se tornaria "a" alternativa para "ganhar a vida". No caso dos membros das familias dos entrevistados, trabalhar numa região industrial como assalariados alterou substantivamente o seu modo de produzir e de reproduzir a existência.

As mulheres aprenderam a produzir sapatos através da observação cotidiana de seus colegas mais experientes. Agora, já não eram os membros da familia que funcionavam como mestres, mas, sim, os trabalhadores mais antigos. Destacaram que trabalhar na fábrica lhes dava uma profissão. A 
tarefa a ser realizada e os resultados a serem alcançados seriam determinados agora pelo chefe, bem diferente do que ocorria quando estavam vivendo no campo. Em troca do trabalho, receberiam um salário. A coopetação capitalista, necessária à realização do trabalho na indústria, não foi identificada pelas mulheres como cooperação. Cooperação na indústria foi associada à amizade, compreensão e atitudes de escuta e apoio entre os colegas trabalhadores assalariados. Explicaram a forma de ser e de organizar o trabalho da indústria como sendo "da natureza da fábrica".

Ao narrarem a sua experiência na cooperativa, as mulheres disseram que assumiam diferentes tarefas e que a decisão era coletiva, ocorrendo através de um processo sistemático de deliberações tomadas em assembléias dos associados. As avaliações sistemáticas, as assembléias e as reuniões ocorridas na cooperativa estavam se constituindo num aprendizado permanente de cooperação. As mais antigas do corpo de sócios fizeram cursos de formação para cooperativismo e referiram-se a eles como muito positivos porque receberam preciosos ensinamentos sobre cooperativismo. Todas contaram que trouxeram em sua bagagem, quando foram trabalhar na cooperativa, muitos saberes profissionais aprendidos e desenvolvidos no chão de fábrica da grande indústria. Na cooperativa, continuavam a aprender com a grande indústria, em função da inserção da cooperativa na cadeia produtiva do calçado. A demanda de treinamento em serviço era grande para poderem atender aos padrões de qualidade exigidos pela indústria contratante. As habilidades, as atitudes e os valores associados à cooperação foram aprendidos, então, prioritariamente no cotidiano de trabalho na cooperativa. Estes foram comparados aos do trabalho e ao jeito de viver e conviver no campo.

As narrativas dos homens a respeito das vivências de trabalho e dos aprendizados de cooperação indicaram alguns aspectos que se diferenciam dos mencionados pelas mulheres. Além do trabalho doméstico, agrícola, industrial e aquele realizado na cooperativa, os homens destacaram vivências de militância sindical e em atividades comunitárias promovidas pela Igreja Católica. Chama a atenção o papel que estas tiveram na sua formação para a gestão da cooperativa e para o exercício de liderança: falar em público, coordenar reuniões, negociar com diferentes forças políticas, com empresários e com representantes de diferentes instituições da sociedade. 
O exercício da liderança na cooperativa implicava uma realimentação e atualização desses saberes, aprendidos alhures. Do ponto de vista dos saberes necessários para produzir calçados, a narrativa dos homens é muito similar à das mulheres. Chamou também a atenção, no caso dos homens, que somente eles estavam diretamente envolvidos com o "produto próprio", um modelo de calçado criado por eles. De forma tímida, estavam ensaiando a realização do sonho de não depender da venda da força coletiva de trabalho da cooperativa para as indústrias de calçado da região. Desafio que, como indicamos anteriormente, não foi vencido.

Cabe comentar ainda que, nas narrativas de todos, a formação escolar foi importante no que diz respeito a conhecimentos de leitura, escrita e Matemática que foram úteis para que pudessem dar conta das dimensões jurídicas e de organização burocrática da cooperativa, mas não foi importante para aprendizagens técnicas. Quanto a aprendizados relacionados ao etos de uma cooperativa, a escola foi pouco lembrada no sentido de ter contribuido para o desenvolvimento de valores e procedimentos de cooperação. Como já indicado em outro lugar neste texto, a familia e o trabalho no campo foram fortemente lembrados como lugares de aprendizagem de cooperação.

A sistematização das reflexões sobre saberes de cooperação dos entrevistados, as transcrições das entrevistas na íntegra e as fotos tiradas nas visitas foram entregues aos sujeitos no formato de um caderno. Tomar em suas mãos fragmentos de sua história, além de causar prazer, provocou-os a confirmar a importância, que já haviam mencionado durante as entrevistas e os encontros coletivos, de se fazer um processo semelhante com todos os associados. A expectativa era de que contribuiria para avançar no comprometimento e entendimento coletivo da história e dos sentidos de fazer parte daquela cooperativa. Vale lembrar que muitos associados, especialmente os mais jovens, não tinham os mesmos elos com a cooperativa. Apesar de participarem das assembléias, muitos tinham um vínculo econômico com a cooperativa. Aparentemente, afirmou-se a hipótese de que a recuperação e a valorização da história pessoal e do que se aprende através dela contribuem para a compreensão do sujeito como ser histórico. 


\section{Notas finais}

A potencialidade e os limites do ser humano na condução de sua história, especialmente no que diz respeito aos modos de produção de sua existência, podem e devem tornar-se conscientes para os trabalhadores em cada situação singular em que se encontram. Assim, assumirmos a tarefa de conhecer, analisar e identificar processos de produção de saberes e os próprios saberes em situações de trabalho atuais e pregressas com os trabalhadores torna-se, para nós, mais candente a cada vez que nos aproximamos de experiências como esta relatada. A pesquisa-formação na perspectiva biográfica contribui para a recuperação do sujeito e do ator, contrapondo-se à hegemonia de modelos deterministas de diferentes matizes paradigmáticas. Tal perspectiva valoriza a dimensão de intencionalidade e, portanto, de escolha do ser humano.

A originalidade da metodologia de pesquisa formação em História de vida situa-se, em primeiro lugar, em nossa constante preocupação em que os autores dos relatos cheguem a uma produção de conhecimento que faça sentido para eles, que se engajem, eles próprios, num projeto de conhecimento que os institua como sujeitos (JOSSO, 1999, p. 15).

A possibilidade de circular livremente na cooperativa, observando o processo de trabalho e os sujeitos em atividade, bem como os depoimentos obtidos nas entrevistas nos indicaram também a relevância da abordagem ergológica. À época, a pesquisa-formação na perspectiva da abordagem biográfica temática deu sustentação para dar mais um passo na reflexão sobre produção de saberes em situação de trabalho ao longo da vida. Conhecer a atividade de trabalho com os trabalhadores, através de procedimentos metodológicos de confrontação e autoconfrontação com o uso de fotos ou filmagens, permitiria conhecer melhor, em diálogo com os trabalhadores, as relações entre o seu patrimônio de saberes e o enfrentamento dos desafios cotidianos no trabalho. Isto é, contribuiria para uma compreensão mais profunda das dramáticas do uso de si na gestão cotidiana do trabalho individual e coletivo na cooperativa. $E$, neste sentido, a produção de novos saberes que acontece no trabalho real. Schwartz (2007, p. 149) afirma que há uma dupla antecipação, quando discute os saberes produzidos em situação 
de trabalho. $\mathrm{O}$ de antecipar a atividade, e, ao mesmo tempo, a própria atividade é antecipadora de saberes que esperam ser conceituados. Esta dupla antecipação permite conhecer o trabalho e preparar-se para ele. É, então, um processo permanente de formação.

Então, para poder conceber uma "formação ao longo de toda vida" - ou para conceber dispositivos de formação profissional que façam jus a essa complexidade do trabalho, que façam a gestão desta dupla antecipação - é preciso, na origem, uma espécie de filosofia prévia do que seja a humanidade, do que seja a humanidade no trabalho, sabendo-se que a humanidade no trabalho implica sempre uma gestão complexa, dispendiosa em energia e, diria eu, dispêndios em dificuldades, que exige arbitragens de valores, na dialética do que é antecipado pelos saberes e do que é permanentemente recomposto pela atividade (SCHWARTZ, 2007, p. 150).

Para finalizar, apresentamos um questionamento feito pelo presidente da cooperativa, que até hoje nos faz pensar. Após muito conversar sobre a história e os desafios atuais que enfrentava no trabalho, questionou, com um ar pensativo: "Estou ainda por entender o que é isso mesmo... Uma cooperativa?". Fica a nossa pergunta: que procedimentos metodológicos auxiliam os implicados - pesquisadores, educadores, trabalhadores - a compreenderem em profundidade as experiências de trabalho associado e que deveriam sustentar propostas de formação para eles? Acreditamos que a abordagem biográfica da pesquisa-formação e a Ergologia trazem algumas pistas importantes para responder a este desafio.

\section{Notas}

1 Inédito viável é uma expressão de Paulo Freire, dialeticamente associada à expressão situações-limite. Refere-se às condições dadas que impedem a realização das possibilidades ontológicas do ser humano de "ser mais" e precisam ser tomadas como objeto de investigação e de ação. Diz 
Freire (1993, p. 11): "Nas situações-limite, mais além das quais se acha o 'inédito viável', às vezes perceptivel, às vezes, não, se encontram razões de ser para ambas as posições: esperançosa e desesperançosa".

2 Industrioso é um adjetivo associado à indústria no sentido da “[...] qualidade humana de aplicação ou esforço sistemático [...]. Industrioso, com o sentido de habilidoso ou assíduo, era o adjetivo derivado comum a partir do século XVI" (WILLIAMS, 2007, p. 230-231).

3 A Ergologia apóia-se no acúmulo de conhecimentos e experiências da linha francesa da Ergonomia. Os conceitos de trabalho prescrito e trabalho real advêm daí.

4 O Departamento de Ergologia originou-se do Dispositivo de Análise Pluridisciplinar de Situações de Trabalho (APST), que foi criado em 1983-1984 pelos professores Yves Schwartz, Daniel Faïta e Bernard Vuillon.

5 Três produções acadêmicas condensam reflexões teóricas e análises de experiências que têm se orientado pela Ergologia: Revista Trabalho \& Educa̧ão - Processos de Produção e L egitimação de Saberes. vol. $12, \mathrm{n}$. 1, 2003; Revista Educaşão UNISINOS, vol. 10, n. 2, 2006) CUNHA (2007b).

6 O acúmulo teórico-metodológico da Ergonomia, especialmente a matriz francesa, tem sido fonte importante para os estudos da Ergologia, especialmente no que diz respeito aos conceitos de trabalho prescrito e trabalho real.

7 "Alguma coisa que atravessa tanto o intelectual, o cultural, quanto o fisiológico, o muscular, o sistema nervoso" (SCHWARTZ, 2007, p. 44).

8 Informações mais abrangentes da implementação desse perfil de cooperativas de calçados na região do Vale do Rio dos Sinos podem ser encontradas em Lima (2008).

9 Não foi possível realizar o momento do "caminhar com" com o grupo de homens entrevistados em função das dificuldades que estavam enfrentando, naquele período, no trabalho. 


\section{Referências}

BRITO, José Eustáquio. Reflexões epistemológicas sobre a ergologia. In: REUNIÃO ANUAL DA ASSOCIAÇÃO NACIONAL DE PÓSGRADUAÇÃO E PESQUISA EM EDUCAÇÃO, 29, 2006, Caxambu. Anais... Rio de Janeiro: ANPED, 2006. CD-Rom.

CUNHA, Daisy Moreira. Notas conceituais sobre atividade e corpo-si na abordagem ergológica do trabalho. In: REUNIÃO ANUAL DA ASSOCIAÇÃO NACIONAL DE PÓS-GRADUAÇÃO E PESQUISA EM EDUCAÇÃO, 30, 2007., Caxambu, Anais... Rio de Janeiro: ANPED, 2007a. CD-Rom.

CUNHA, Daisy Moreira. A educação aprende com o homem e a vida. In: CUNHA, Daisy Moreira (Org.). Trabalbo, minas e saberes. Belo Horizonte: NETE/FAE/UFMG, 2007b. p.193-210.

FREIRE, Paulo. Pedagogia da esperança. um reencontro com a pedagogia do oprimido. Rio de Janeiro: Paz e Terra, 1993.

JOSSO, Marie-Christine. Experiência de vida e formação. São Paulo: Cortez, 2004.

JOSSO, Marie-Christine. História de vida e projeto: a história de vida como projeto e as "histórias de vida" a serviço de projetos. Educafãa e Pesquisa, São Paulo, v. 25, n. 2, p.11-23, jul. 1999.

LIMA, Jacob Carlos. Reestruturação industrial, desemprego e autogestão: as cooperativas do Vale dos Sinos. Sociologias, Porto Alegre, n.19, p. 212 249, jan./jun. 2008.

REVISTA EDUCAÇÃO UNISINOS. São Leopoldo, v.10, n.2, maio/ ago. 2006.

SCHWARTZ, Yves. Trabalho e saber. Trabalbo e Educafão: Revista do NETE, Belo Horizonte, v. 12, n.1, p. 21-34, jan./jun. 2003.

SCHWARTZ, Yves; DURRIVE, Louis (Org.). Trabalbo e Ergologia. conversas sobre a atividade humana. Rio de Janeiro, Niterói: Editora da UFF, 2007.

SINGER, Paul. Economia Solidária. In: CATTANI, Antonio David (Org.). A outra economia. Porto Alegre: Veraz, 2003. p.116-125. 
VENDRAMINI, Célia Regina. A contribuição de E. P. Thompson para a apreensão dos saberes produzidos do/no trabalho. Educação Unisinos, São Leopoldo, v.10, n. 2, p.123-129, 2006.

WILLIAMS, Raymond. Indústria. In: WILLIAMS, Raymond. Palavraschave: um vocabulário de cultura e sociedade. São Paulo: Boitempo, 2007. p. $230-234$. 
The worker at the center of educational research for associated workers

\begin{abstract}
:
The objective of this article is to analyze and prepare theoretical-methodological presumptions for educational projects aimed at the affirmation and autonomy of individuals involved in associated labor experiences. Its framework is the struggle for labor and a society in which the principal of selfmanagement is a fundamental pillar. The paper analyzes the potential for an ergological approach to work and to the theoretical perspective known as a biographical thematic approach (life stories to support project development).
\end{abstract}

Key words: Labor. Worker Education. Workers-Experiences.
Le travailleur au centre de propositions de reherche-formation pour le travail associé

\section{Résumé:}

Les réflexions présentées dans cet article visent à contribuer à l'élaboration et l'analyse des présupposés méthodologiques de projets dirigés vers l'affirmation et l'autonomie de sujets engagés dans un travail associatif. Ce dernier peut être caratérisé comme une lutte politique en faveur d'un travail et d'une société où le principe d'autogestion est affirmé comme un des piliers fondamentaux. En ayant cela en vue, l'autheur de l'article analise le potentiel d'une approche ergologie du travail en utilisant un référentiel théorique appliqué à des Biographies Formatrices.

Mots-clés: Travail. Travailleurs-

Formation. Travailleurs-expériences.

\author{
Maria Clara Bueno Fischer \\ Endereço residencial \\ Rua Ramiro Barcelos, 1410/602 Porto Alegre - RS \\ CEP: 90035-002 \\ Telefone: (51) 3312-8626 \\ E-mail: clarafis@cpovo.net \\ Endereço de trabalho \\ Av: Unisinos, 950 - São Leopoldo - RS \\ CEP: $93022-000$ \\ Telefone: (51) 2591-1100 \\ Fax: (51) 3590-8118
}

Recebido em: $15 / 4 / 2008$

Aprovado em: 18/7/2008 